\title{
MULTIPLE SCLEROSIS IN BRITISH COMMONWEALTH COUNTRIES IN THE SOUTHERN HEMISPHERE
}

\author{
BY \\ E. D. ACHESON \\ From the Nuffield Department of Clinical Medicine, Oxford University
}

In the United States of America, which extend from approximately $26^{\circ}$ to $49^{\circ}$ North, the suggestion that a four-fold increase in the frequency of multiple sclerosis occurred between $30^{\circ}$ and $40^{\circ}$ was originally based on crude mortality data (Limburg, 1950). Recent detailed field studies have confirmed this impression (Kurland, 1952; Alter, Allison, Talbert, and Kurland, 1960; Kurland, Mulder, and Westlund, 1955). In ex-servicemen of the U.S. Armed Forces, a close correlation has also been demonstrated between the latitude of their place of birth and the frequency with which they subsequently developed miltiple sclerosis (Acheson, Bachrach, and Wright, 1960). This relationship appears to hold not only for white veterans but for Negroes (Acheson and Bachrach, 1960). All North American studies agree that the disease is rare in the states of the deep South (Limburg, 1960; Kurland, 1952; Alter and others, 1960). In Europe, multiple sclerosis is certainly at least as prevalent in the British Isles (Allison and Millar, 1954; Miller, Ridley, and Schapira, 1960; Sutherland, 1956) and the northern and central Continental countries (Hyllested, 1956; Bammer and Schaltenbrand, 1960; Dassel, 1960; Georgi and Hall, 1960 ) as in the Northern States of America, and may be less frequent along the Mediterranean littoral. These differences have been interpreted as suggesting that there is an important, but as yet unknown, environmental factor correlated with latitude in the aetiology of multiple sclerosis (Kurland and others, 1955; Acheson and Bachrach, 1960). The alternative view that the geographical distribution is due to differences in racial susceptibility, or to differences in diagnostic standards, is becoming more difficult to maintain, particularly in regard to the distribution of the disease in the United States.

If an environmental factor which varies with latitude is important in multiple sclerosis, it should be possible to demonstrate a fluctuation in the frequency of the disease within the settler populations of the southern hemisphere. Indeed the white people of New Zealand, Australia, and South Africa are particularly suitable for such a study, because an overwhelming majority of their forebears came from susceptible stock from the British Isles or Holland $\left(50^{\circ}-60^{\circ} \mathrm{N}\right.$.) whereas their descendants now live over a much wider range of latitude in the southern hemisphere (from $22^{\circ}-47^{\circ} \mathrm{S}$.). This being so, if the environmental hypothesis is correct, we should expect the disease to diminish from a frequency somewhat less than that of England and Wales (mean latitude $52 \cdot 5^{\circ} \mathrm{N}$.) in the South Island of New Zealand (mean latitude $44^{\circ} \mathrm{S}$.) to extreme rarity in the Transvaal and Orange Free State. In the present paper mortality data has in general been used, as apart from Dean's preliminary report from South Africa (Dean, 1949) information about morbidity is not yet available. For New Zealand, however, hospital discharge rates have also been obtained. Some comparisons have been made between the multiple sclerosis data and the death rates experienced in these countries from amyotrophic lateral sclerosis.

MATERIAL

Information was obtained from the Departments of Medical Statistics of the various countries concerning deaths attributed to rubrics 345 (multiple sclerosis) and 356 (motorneurone disease; amyotrophic lateral sclerosis) of the Sixth Revision of the International Statistical Classification(W.H.O., 1948) during the years 1950-9 for the States of Australia, the Islands of New Zealand, and the Union of South Africa. Only data concerning whites were considered. As the populations concerned are small, average death rates for the decade were computed from the 1950-9 aggregates, using the best estimates 
available for the white populations for 1954. Similar data for the years 1954-6 were collected for the countries of origin of the white stock under study, namely England and Wales, Scotland, and Northern Ireland. The proportion of all deaths over the age of 65 attributed to "senility, senile decay, etc., without mention of psychosis" (rubric 794 I.S.C.) was used as a rough index of the standard of death certification in the countries under study.

\section{RESULTS}

Fluctuation with Latitude and with Sunshine. Estimates were made of the mean latitudes of the populations under study in the following manner. In Australia, where a little more than half of the population lives within the metropolitan areas of the state capitals, the latitude of these capitals were taken as representative of the bulk of the population of the six states. For New Zealand, where the bulk of the population is clustered at the extremities of the two islands, the mean latitude of the North Island was estimated as $39^{\circ} \mathrm{S}$. and of the South Island $44^{\circ} \mathrm{S}$. For South Africa, where the principal white population centres of the Cape $\left(33 \cdot 5^{\circ}\right)$ and the Rand $\left(26^{\circ}\right)$ are widely separated, $29 \cdot 5^{\circ} \mathrm{S}$. was taken as a representative figure for the whole white population. For
England and Wales, Scotland, Northern Ireland, and the Irish Republic, the latitudes of Birmingham, Edinburgh, Belfast, and Dublin respectively were used. For the four Census Regions of the United States and for Canada, the representative places taken were Atlanta (South), San Francisco (West), Chicago (North Central), New York (North East), and Ottawa. These estimates are probably correct within half a degree. For Australia, New Zealand, South Africa, and the United Kingdom, estimates of the average total annual hours of sunshine at the points stated (as measured by the Campbell-Stokes instrument) were also obtained (Brooks, 1950; Garnier, 1958; Government of S. Africa; Annual Abstract of Statistics, 1958). North American figures could not be used as they are not recorded in a comparable way (Gorczynski, 1948).

The average age-adjusted death rates from multiple sclerosis and amyotrophic lateral sclerosis are shown in the Table. It can be seen at once that, whether taken individually or as a group, the death rates from multiple sclerosis in the countries of origin (British Isles) are higher than in any of the white settler populations of the southern hemisphere. For motorneurone disease, on the other hand, there is no gross difference between the British age-adjusted

TABLE

AVERAGE AGE-ADJUSTED DEATH RATES FROM MULTIPLE SCLEROSIS AND AMYOTROPHIC LATERAL SCLEROSIS

\begin{tabular}{|c|c|c|c|c|c|c|c|c|c|c|}
\hline \multirow[b]{2}{*}{ Country } & \multirow[b]{2}{*}{$\begin{array}{c}\text { Estimated } \\
\text { Population } \\
\text { (thousands) }\end{array}$} & \multirow[b]{2}{*}{$\begin{array}{l}\text { Average } \\
\text { Total } \\
\text { Annual } \\
\text { Hours of } \\
\text { Sunshine }\end{array}$} & \multirow[b]{2}{*}{$\begin{array}{c}\text { Mean } \\
\text { Latitude } \\
\left(^{\circ}\right)\end{array}$} & \multicolumn{3}{|c|}{ Multiple Sclerosis } & \multicolumn{3}{|c|}{ Amyotrophic Lateral Sclerosis } & \multirow[b]{2}{*}{$\begin{array}{l}\text { Proportion of } \\
\text { Deaths over } 65 \\
\text { attributed to } \\
\text { Senility within } \\
\text { the Same } \\
\text { Years }\end{array}$} \\
\hline & & & & Deaths & Years & $\begin{array}{l}\text { Average } \\
\text { Age- } \\
\text { adjusted } \\
\text { Death } \\
\text { Rate }\end{array}$ & Deaths & Years & $\begin{array}{l}\text { Average } \\
\text { Age- } \\
\text { adjusted } \\
\text { Death } \\
\text { Rate }\end{array}$ & \\
\hline $\begin{array}{lll}\text { England and } & \text { Wales } & \ldots \\
\text { Scotland } & \ldots & \ldots \\
\text { N. Ireland } & \ldots & \ldots\end{array}$ & $\begin{array}{r}44,623 \\
5,133 \\
1,393\end{array}$ & $\begin{array}{l}1,445 \\
1,220 \\
1,285\end{array}$ & $\begin{array}{l}52 \cdot 5^{\circ} \mathrm{N} \\
56^{\circ} \mathrm{N} \\
54 \cdot 5^{\circ} \mathrm{N}\end{array}$ & $\begin{array}{r}2,453 \\
488 \\
128\end{array}$ & $\begin{array}{l}1954-6 \\
1954-6 \\
1954-6\end{array}$ & $\begin{array}{l}1 \cdot 60 \\
2 \cdot 93 \\
3 \cdot 14\end{array}$ & $\begin{array}{r}1,537 \\
199 \\
32 \\
\end{array}$ & $\begin{array}{l}1954-6 \\
1954-6 \\
1954-6 \\
\end{array}$ & $\begin{array}{l}0.92 \\
1.14 \\
0.70\end{array}$ & $\begin{array}{l}2 \cdot 4 \\
2 \cdot 1 \\
- \\
\end{array}$ \\
\hline UNITED KINGDOM & 51,149 & - & - & 3,069 & & $1 \cdot 77$ & 1,768 & & 0.94 & - \\
\hline 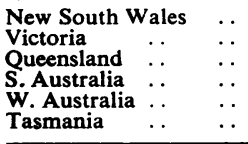 & $\begin{array}{r}3,424 \\
2,452 \\
1,318 \\
797 \\
639 \\
309\end{array}$ & $\begin{array}{l}2,475 \\
2,225 \\
2,700 \\
2,550 \\
2,810 \\
2,120\end{array}$ & $\begin{array}{l}34^{\circ} \mathrm{S} \\
37 \cdot 5^{\circ} \mathrm{S} \\
27 \cdot 5^{\circ} \mathrm{S} \\
35^{\circ} \mathrm{S} \\
32^{\circ} \mathrm{S} \\
42^{\circ} \mathrm{S}\end{array}$ & $\begin{array}{r}223 \\
237 \\
94 \\
52 \\
22 \\
35 \\
\end{array}$ & $\begin{array}{l}1950-9 \\
1950-9 \\
1950-9 \\
1950-9 \\
1950-9 \\
1950-9 \\
\end{array}$ & $\begin{array}{l}0.65 \\
0.96 \\
0.76 \\
0.67 \\
0.37 \\
1.25 \\
\end{array}$ & $\begin{array}{l}326 \\
254 \\
115 \\
84^{*} \\
50 \\
25 \\
\end{array}$ & $\begin{array}{l}1950-9 \\
1950-9 \\
1950-9 \\
1953-9 * \\
1950-9 \\
1950-9\end{array}$ & $\begin{array}{l}0.95 \\
1.01 \\
0.90 \\
1.45 \\
0.82 \\
0.89 \\
\end{array}$ & $\begin{array}{l}3 \cdot 3 \\
1.8 \\
2.7 \\
2 \cdot 8 \\
0.7 \\
1.5 \\
\end{array}$ \\
\hline AUSTRALIA & 8,986 & - & - & 663 & & $0 \cdot 74$ & 890 & & 1.00 & $2 \cdot 5$ \\
\hline $\begin{array}{l}\text { North Island .. } \\
\text { South Island .. } \\
\end{array}$ & $\begin{array}{r}1,283 \\
646 \\
\end{array}$ & $\begin{array}{l}2,050 \\
1,850 \\
\end{array}$ & $\begin{array}{l}39^{\circ} \mathrm{S} \\
44^{\circ} \mathrm{S} \\
\end{array}$ & $\begin{array}{r}130 \\
81 \\
\end{array}$ & $\begin{array}{l}1950-9 \\
1950-9\end{array}$ & $\begin{array}{l}1.02 \\
1.31 \\
\end{array}$ & $\begin{array}{r}170 \\
84 \\
\end{array}$ & $\begin{array}{l}1950-9 \\
1950-9\end{array}$ & $\begin{array}{l}1 \cdot 25 \\
1.20 \\
\end{array}$ & $\begin{array}{l}1.2 \\
0.9 \\
\end{array}$ \\
\hline NEW ZEALAND & 1,929 & - & - & 211 & & $1 \cdot 16$ & 254 & & $1 \cdot 24$ & $1 \cdot 1$ \\
\hline $\begin{array}{c}\text { UNION OF SOUTH } \\
\text { AFRICA }\end{array}$ & 2,642 & 3,000 & $29 \cdot 5^{\circ} \mathrm{S}$ & 22 & $1950-8$ & $0.09 t$ & 68 & $1950-8$ & $0 \cdot 31$ & - \\
\hline
\end{tabular}

* 1950-2 figures not available. An estimate of 120 deaths $\left(84 \times \frac{10}{7}\right)$ was therefore used in computing the average annual death rate for the whole of Australia, 1950-59.

†Provincial death rates: Natal 0.2; Cape 0.07; Transvaal and Orange Free State 0.06.

Notes; The figures for Australia, New Zealand, and South Africa are for the white population. For Australia no deaths from multiple sclerosis or amyotrophic lateral sclerosis were reported within the small populations of the Northern Territory or the Australian Capital Territory. 
rate* $(0.94$ per 100,000$)$ and the New Zealand and Australian rates $(1.24$ and 1.00 per 100,000$)$. The South African figure is an exception and is lower.

The age-adjusted death rates for multiple sclerosis and motorneurone disease was plotted against latitude in Fig. 1. For the northern hemisphere (circles), in addition to the United Kingdom, figures for the Irish Republic (W.H.O., 1956) (dotted circles), the regions of the United States (whites), and Canada (Kurland, 1952) are also given. The figures for the Irish Republic have not been used in the regression as information about the current coding policy for deaths attributed to cerebral sclerosis, etc., was not obtained. In the northern hemisphere the correlation between the multiple sclerosis rates and latitude is highly significant $(r=+0 \cdot 90 ; \cdot 001<p<\cdot 01)$ and a similar degree of correlation is present for the states (dots) in the southern hemisphere $(r=+0 \cdot 86 ; \cdot 001<$

*All death rates were adjusted to the structure of the United States population in 1950 . $p<\cdot 01)$. The line drawn in Fig. 1(a) represents the regression equation for the northern hemisphere, and it is striking how well it fits the values for the southern hemisphere. The steep gradient of the line is also notable, indicating an increase in reported death rate of 1.05 per 100,000 per $10^{\circ}$ of latitude. Queensland is the only striking exception to the general trend.

For motorneurone disease the situation is different. In the northern hemisphere (circles) there is a relationship with latitude $(r=+0.79 ; p=0.02)$. However, the gradient is slight and there is an increase in death rate of only 0.16 per 100,000 per $10^{\circ}$ of latitude. Similar correlations and gradients can be shown for other diseases within the regions of the United States, Canada, and England and Wales, notably regional enteritis (Acheson, 1959, p. 481), ulcerative colitis (Acheson, 1959, p. 469) and Parkinsonism (Kurland, 1959), and these are probably related to differences in the standard of death certification from South to North within these countries. For the

Southern Hemisphere

- Northern Hemisphere

- Irish Republic (latitude $50^{\circ}$ )

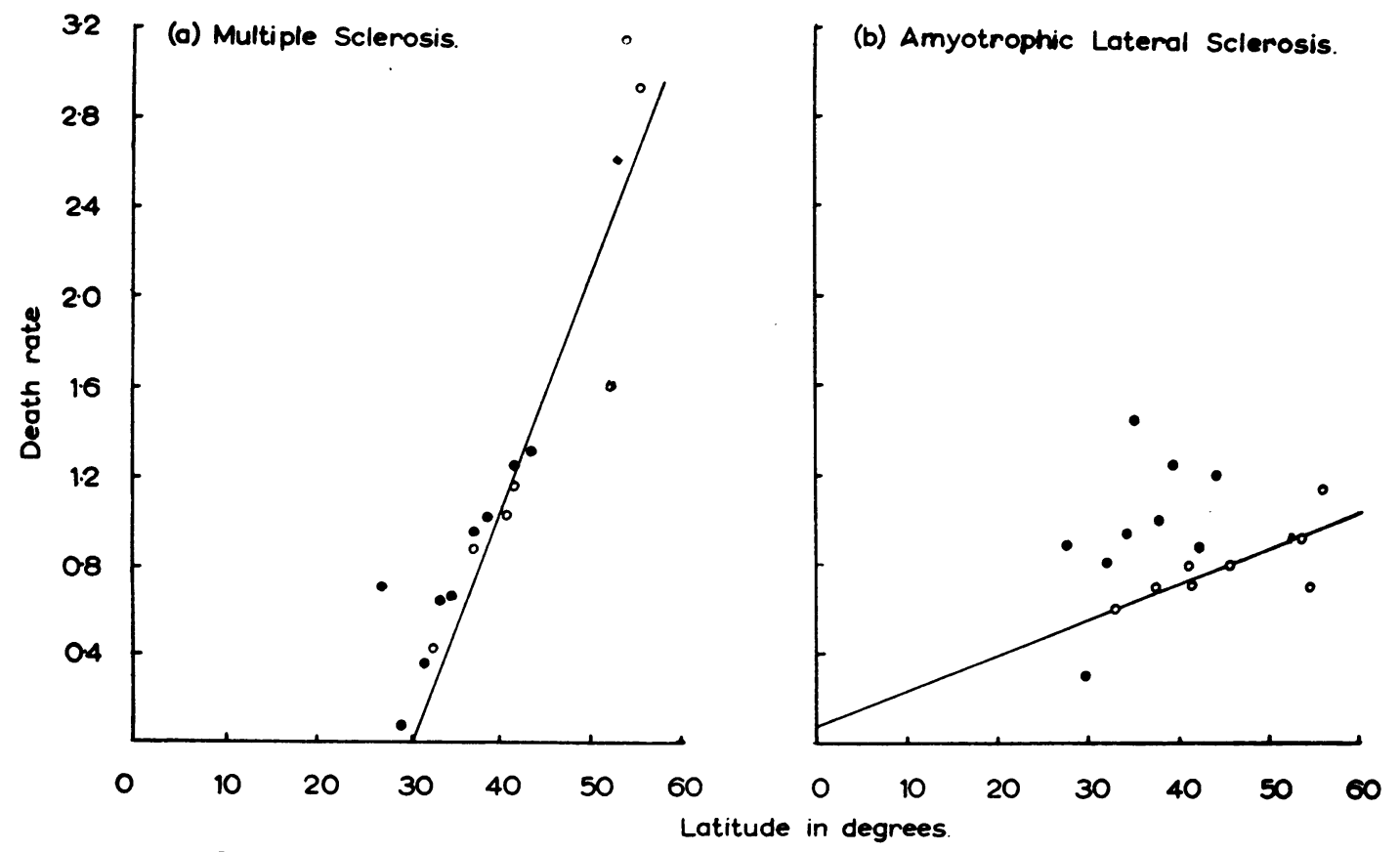

Fig. 1.-Average death rates by mean latitude. (a) multiple sclerosis (b) amyotrophic lateral sclerosis.

(a) The equation of the line (average age-adjusted death rate for multiple sclerosis, regions of the U.S., Canada, England and Wales,

(b) The equation for the corresponding line for amyotrophic lateral sclerosis is $y=0.0159 x+0.0755$. 
southern hemisphere (dots), however, there is no significant correlation between mortality from motorneurone disease and latitude $(r=+0 \cdot 51$; $p>0 \cdot 1)$, although a trend is present in this direction. It is also noteworthy that the line drawn in Fig. 1(b) for the northern hemisphere does not describe the data from the southern hemisphere.

The proportion of deaths over the age of 65 attritubed to the unsatisfactory diagnosis "senility or senile decay without mention of psychosis" (Table I) was taken as a rough index of the standard of death certification in each country. It was found that there was a tendency for the States of Australia nearer the Equator to have a higher proportion of deaths certified under this heading than the more southerly states. This suggests an inverse relationship between standard of death certification and latitude such as can be demonstrated by using the same criteria within the United States (U.S. Dept. of Health). In fact, this relationship is not at all well-marked within the countries under study in the southern hemisphere.
Thus, in New Zealand, the proportions for the two islands are not significantly different; and, for the components of Australia and New Zealand together, the correlation coefficient (proportion of deaths over 65 years ascribed to senility versus latitude) is only $-0.51(p>0 \cdot 1)$.

When the death rates ascribed to multiple sclerosis, amyotrophic lateral sclerosis, and "senility" were correlated with the average total annual hours of sunshine, a highly significant negative correlation (the more sunshine received, the lower the death rate experienced) was obtained for multiple sclerosis $(r=-0.95 ; p<0.001)$ but not for amyotrophic lateral sclerosis $(r=-0 \cdot 62 ; \cdot 05<p<\cdot 1)$. For "senility" there was no material trend $(r=+0 \cdot 39)$.

Age- and Sex-Specific Rates. - The average agespecific death rates from multiple sclerosis by sex for Australia, New Zealand, and England and Wales are shown in Fig. 2. (The number of deaths reported from South Africa is too small to be handled in this way.) The graphs for England and Wales and New

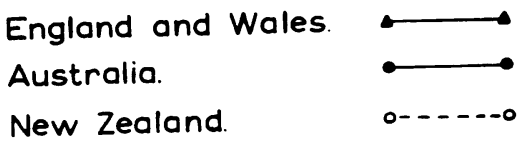

(a) Males

(b) Females.

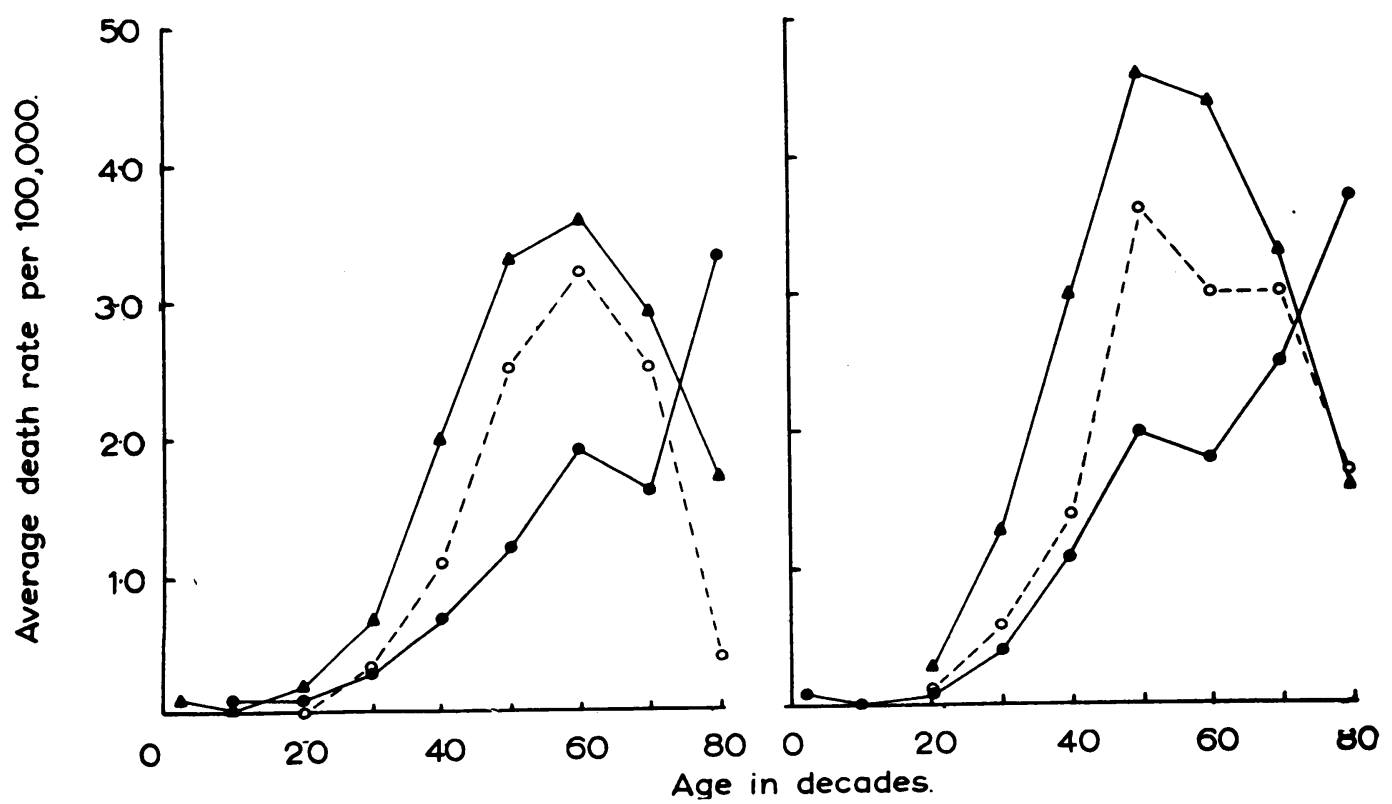

FIG. 2.-Average age-specific death rates from multiple sclerosis, by sex for England and Wales (1954-6), New Zealand (1950-9), and Australia (1950-9). 
Zealand are strikingly similar in form, with peaks in the 45 to 54 year age group in women and the 55 to 64 year age group in men. The symmetrical form of these curves closely resembles the age-specific prevalence curves found in recent American (Kurland, 1952; Alter and others, 1960) and British (Allison and Millar, 1954) surveys, although the peaks of prevalence fall, as expected, 10 to 20 years earlier. The age-specific curves for Scotland and Northern Ireland, which are not shown here because of lack of space, also exhibit a peak in middle age followed by a decline. The Australian age-specific curves are biphasic, with the first peak at 45 to 54 years and 55 to 64 years for females and males respectively, followed by a slight fall, and then by a second steep rise in old age. Such curves suggest an admixture of two disease entities. It is possible that, in spite of the recent change in death certification procedure*, there is still some confusion in the classification of cerebral arteriosclerosis and multiple sclerosis. A much less likely alternative is that the age-pattern of deaths due to multiple sclerosis differs in Australia. The published curves for the United States and Canada show a steady increase with age and resemble the Australian curve more closely than those for New Zealand and England and Wales.

A consistent female:male ratio of $1 \cdot 4: 1$ was found when the average sex-specific death rates from multiple sclerosis were compared for Australia, New Zealand, South Africa, England and Wales, Scotland, and Northern Ireland. Such an effect was not observed for mortality from multiple sclerosis in the United States or Canada, but recent American morbidity studies have agreed that the prevalence of the conditions is higher in women than in men.

Secular Trend.-Within the period 1950-59, there has been no consistent trend in the crude death rate from multiple sclerosis in New Zealand or Australia. For South Africa the reported deaths are too few to permit annual rates to be compared but there appears to have been an increase in the mortality ascribed to multiple sclerosis since 1956.

Morbidity Data.-In New Zealand the vast majority of all hospital admissions take place within the National Service, which operates to an equal extent throughout both Islands. A central diagnostic index is kept. When duplicate admissions for the same person had been eliminated, it was found that, within the years 1950-7, a total of 617 white persons had

*In Australia, New Zealand, and England and Wales (Registrars General) "cerebral sclerosis" and "general sclerosis" are now coded to arterio-sclerosis unless the certifying practitioner indicates that the Registrars report that these terms are very rarely used on death certificates. been discharged from or had died in New Zealand public hospitals with multiple sclerosis, an overall hospitalization rate of 4 per 100,000 per annum. In the same period nine Maoris had been hospitalized, giving an average annual rate of 0.9 per 100,000 . When the European rates for the North and South Islands were considered separately, it was found that the average annual discharge rate for the South Island $(5 \cdot 0 \pm 0 \cdot 31$ per 100,000$)$ exceeded that for the North Island $(3 \cdot 5 \pm 0 \cdot 19$ per 100,000$)$. This difference is statistically significant $(\cdot 001<p<\cdot 01)$. The age-specific discharge rates by sex for each island are seen in Fig. 3 (opposite).

\section{Discussion}

The object of this paper has been to test in the southern hemisphere the hypothesis derived from data from the northern hemisphere that, within peoples of European stock, the frequency of multiple sclerosis is related to latitude. If mortality data represent an index of the frequency of multiple sclerosis, the hypothesis has withstood the test. Thus, not only has a correlation with latitude of similar magnitude been demonstrated for the southern hemisphere, but the regression equation for the northern hemisphere (which states the hypothesis under examination in mathematical form) adequately describes the data for the southern hemisphere with the exception of Queensland.

Unfortunately, in chronic diseases, it cannot be assumed that mortality is an index of morbidity without careful scrutiny. Hyllested (1956) has pointed out that in Denmark only about half of the known cases of multiple sclerosis are at death certified as having died of that disease. On the other hand, Sutherland (1956) in Scotland, found slightly more deaths certified than he would have expected from his field study. Kurland and Moriyama (1951), in a survey of death certificates from the United States and Canada, found that in 1946 the death rates attributed to multiple sclerosis were inflated by about 20 per cent. with cases of "cerebral arteriosclerosis". Fortunately this term and the other ambiguous term "general sclerosis" is reported as being used rarely (less than 2 per cent. of all deaths in rubric 345) in the British Isles, and since 1950 this has been the subject of further inquiry by the Registrars of all countries under study except South Africa. However, it is prudent to assume that the mortality ascribed to multiple sclerosis is still subject to large errors of both under-reporting and misreporting.

In spite of these acknowledged errors, Limburg (1950) drew the conclusion from crude mortality data that multiple sclerosis became more frequent 


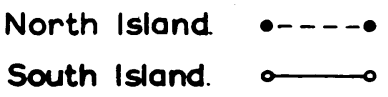

(a) Females.

(b) Males.

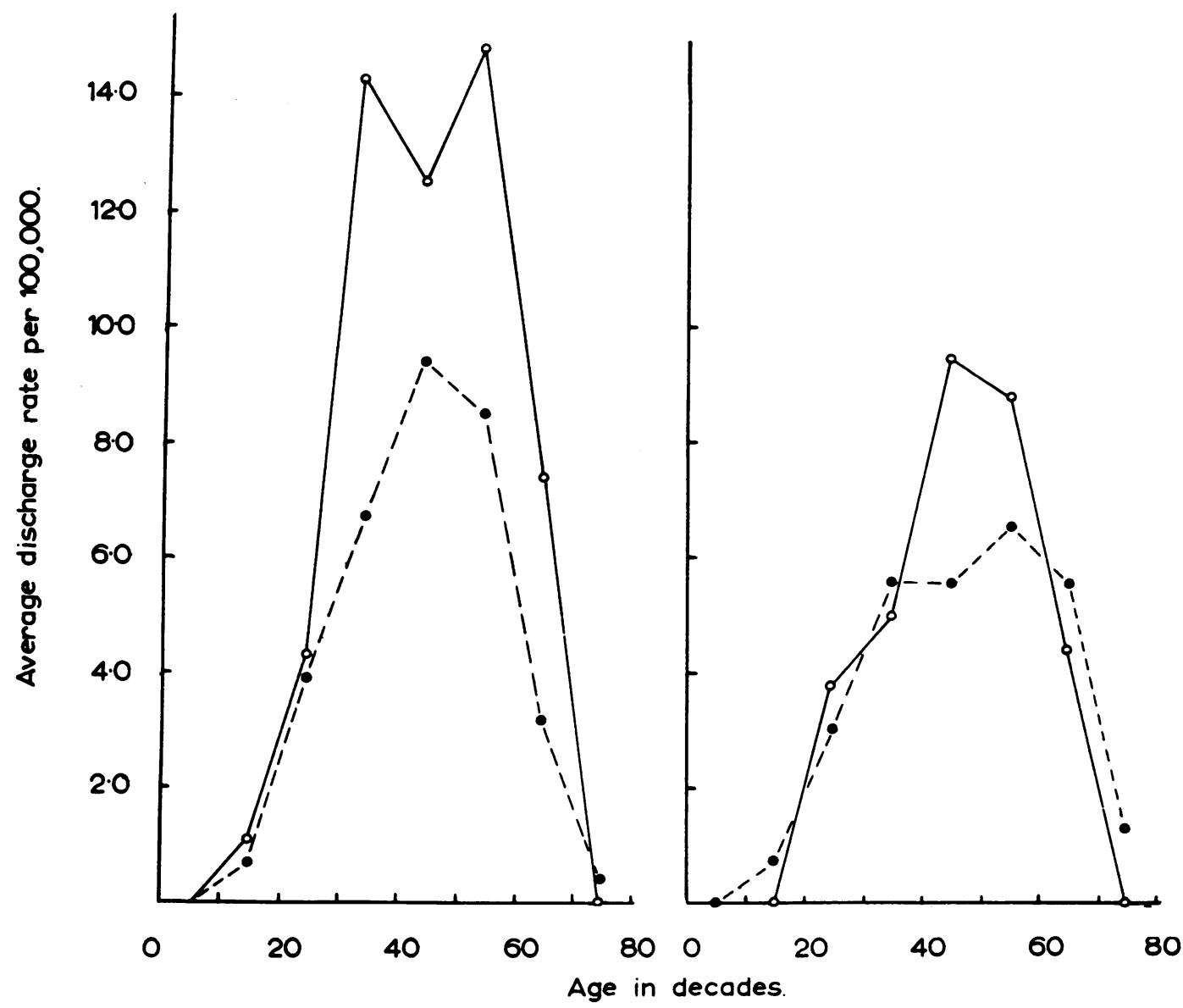

Fio. 3.-Discharge rates (multiple sclerosis) from the New Zealand Public Hospitals (1950-7), by age, sex, and Island of residence.

from South to North in North America. Subsequent field studies have confirmed his conclusion in such measure that it has been suggested (Sutherland, 1956, 1959) that an index of local prevalence can be obtained by multiplying the local death rate by the average life expectancy (20 years) (Pratt, Compston, and McAlpine, 1951). Such apparently perilous calculations come close to the observed prevalence $( \pm 20$ per cent.) for Louisiana and South Carolina (Kurland, 1952), Ontario (White and Wheelan, 1958), North Scotland (Sutherland, 1956), and Northern Ireland (Allison and Millar, 1954), but not for Minnesota (MacLean, Berkson, Woltman, and Schionneman, 1950), Colorado (Kurland and Dodge, 1953), California (Kurland and Newman, 1953), Montana (Seidler, Nicholl, and Kurland, 1958), or 
Nova Scotia (Alter and others, 1960), when the crude mortality rates for State or Country are compared with the best available data on local prevalence.

As we have seen, the fluctuation of the frequency of multiple sclerosis with latitude is now beyond doubt within the United States, and factors which vary with latitude have recently been under scrutiny as possible aetiological influences in the disease (Limburg, 1950; Acheson and others, 1960; Barlow, 1960). This increase in frequency in Northern America holds true in spite of the bias introduced by rising standards of medical care from South to North within that country. Whether or not (as mortality figures suggest) the disease is indeed commoner in the British Isles than in the Northern States will only be settled when compact communities like Rochester, Minnesota, and Kingston, Ontario, are surveyed in Great Britain.

The question, whether the decreasing frequency with which multiple sclerosis is reported as a cause of death in the southern hemisphere as the equator is approached is a real phenomenon or is due simply to a consistent increase in under-reporting, cannot be answered finally at the present time. The slight tendency for motorneurone disease* mortality and the mortality attributed to "senility" also to be related to latitude suggests that the standards of death certification may vary with latitude within the southern hemisphere, although the correlations are not significant. On the other hand, the morbidity data from New Zealand support the mortality data in suggesting that multiple sclerosis is more prevalent in the South than in the North Island. Dean (1949) also confirmed that the disease was extremely rare in South Africans of European stock.

It is also of interest that, when the death rates from multiple sclerosis in the southern hemisphere were correlated with average annual hours of sunshine the relationship was marginally closer than that with latitude, although the difference is not significant. In United States veterans (Acheson and others, 1950) the relationship of winter sunshine at birthplace with frequency of multiple sclerosis was slightly closer than the relationship of latitude.

In conclusion, it may be said that, although no epidemiological question about a chronic disease can be settled by mortality data alone, there is sufficient evidence of an environmental influence to warrant careful field studies in Australia and New Zealand. In particular it is important to know whether, as Sutherland and Eadie (1959) have suggested, Brisbane, in spite of its position on the edge of the

- This disease was selected because it also requires a high standard of diagnosis and because its probable genetic aetiology suggests that it may be evenly distributed except in isolated communities. tropical zone, really has an appreciable prevalence of multiple sclerosis, unlike Natal and Louisiana in similar situations. If this is so, the study of such an exception might be rewarding. In South America, Chile and Argentina, which extend over $30^{\circ}$ of latitude, deserve study. It would also be of interest to know the prevalence of multiple sclerosis in the large German community in Santa Catarina State in Brazil $\left(27 \cdot 5^{\circ} \mathrm{S}\right.$.).

\section{SUMMARY}

A study has been made of the mortality ascribed to multiple (disseminated) sclerosis in the white settler populations of Australia, New Zealand, and South Africa within the period 1950-9. A close relationship has been found between the multiple sclerosis death rate (age-adjusted) and latitude, which is very similar to the relationship which exists for the death rate within the English-speaking countries in the northern hemisphere. Some comparisons are made with the mortality rates ascribed to amyotrophic lateral sclerosis during the same period. These fluctuate much less widely. It is concluded that while no final answer can be obtained from mortality data alone, the distribution of deaths ascribed to multiple sclerosis in the Southern hemisphere is sufficiently suggestive of an environmental factor (or factors) similar to those operating in the northern hemisphere to justify local prevalence studies.

Hospital discharge rates for multiple sclerosis for the two islands of New Zealand are also given.

\section{REFERENCES}

Acheson, E. D. (1959). J. chron. Dis., 10, 469, 481.

and Bachrach, C. A. (1960). Amer. J. Hyg., 72, 88. -, and Wright, F. M. (1960). Acta psychiat. scand., 35, Suppl. 147, 132.

Allison, R. S., and Millar, J. H. D. (1954). Ulster med. J., 23, Suppl. 2.

Alter, M., Allison, R. S., Talbert, O. R., and Kurland, L. T. (1960). Wld. Neurol., 1, 55.

Annual Abstract of Statistics (1958). No. 95, "Sunshine Averages, 1921-50".

Bammer, H., and Schaltenbrand, G. (1960). Acta psychiat. scand., 35, Suppl. 147, p. 57.

Barlow, J. S. (1960). Ibid., 35, Suppl. 147, p. 108.

Brooks, C. E. P. (1950)." "Climate in Everyday Life". Benn, London.

Dassel, H. (1960). Acta psychiat. scand., 35, Suppl. 147, p. 64.

Dean, G. (1949). Brit. med. J., 1, 842.

Department of Health, Education and Welfare. "Annual Report, National Office of Vital Statistics". Washington, D.C. 
Garnier, B. J. (1958). "The Climate of New Zealand". Arnold, London.

Georgi, F., and Hall, P. (1960). Acta psychiat. scand., 35, Suppl. 147, p. 75.

Gorczynski, W. (1948). C. R. Soc. Sci. Lettres, Varsovie Classe III, Année 1947.

Hyllested, K. "Disseminated Sclerosis in Denmark". (1956). Jorgensen, Copenhagen. (Cited by Alter and others, 1960).

Kurland, L. T. (1952). Amer. J. Hyg., 55, 457. (1958). J. chron. Dis., 8, 378.

- (1959). "Pathogenesis and Treatment of Parkinsonism". Thomas, Springfield, Ill. and Dodge, H. J. (1953). Neurology, 3, 577.

and Moriyama, I. M. (1951). J. Amer. med. Ass., 145,725 .

- Mulder, D. W., and Westlund, K. B. (1955). New Engl. J. Med., 252, 649, 697. and Newman, H. W. (1953). Calif. Med., 79, 381.
Limburg, C.C.(1950). Res.Publ. Ass. nerv. ment. Dis., 28, 15.

MacLean, A. R., Berkson, J., Woltman, H. W., and Schionneman, L. (1950). Ibid., 28, 25.

Miller, H., Ridley, A., and Schapira, K. (1960). Brit. med. J., 2, 343.

Pratt, R. T. C., Compston, N. D., and McAlpine, D. (1951). Brain, 74, 191.

Siedler, H. D., Nicholl, W., and Kurland, L. T. (1958). Journal-Lancet, 78, 358.

Sutherland, J. M. (1956). Brain, 79, 635.

— and Eadie, M. J. (1959). Brit. med. J., 2, 824.

Weather Bureau, Department of Transport, Pretoria. "Sunshine and Cloudiness in South Africa".

White, D. N., and Wheelan, L. Quoted by Kurland (1958).

W.H.O. (1948). "Manual of the International Statistical Classification of Diseases, Injuries, and Causes of Death (6th Revision)", W.H.O., Geneva.

- (1956). Epidemiological and Vital Statistics Report", vol. 9 , p. 595 . 